\begin{tabular}{|c|c|c|c|}
\hline & \multicolumn{3}{|c|}{ Age of child } \\
\hline & 3 Months & 3 Years & 7 Years \\
\hline$\%$ Of junior doctors unable to give an answer & 15 & 12 & 9 \\
\hline Range of answers given $(\mathrm{J})$ & $5-50$ & $10-100$ & $10-100$ \\
\hline$\%$ Of answers lying between Resuscitation Council guidelines for 10 th and 90 th centiles of weight & 24 & 21 & 38 \\
\hline$\%$ Of answers lying between half and twice Resuscitation Council guidelines for 50 th centile of weight & 44 & 65 & 59 \\
\hline Maximum time to answer (s) & 32 & 16 & 18 \\
\hline Median time to answer (s) & 8 & 6 & 6 \\
\hline
\end{tabular}

respiratory arrest or other urgent conditions. Also included are defibrillator settings and suggestions for initial fluid infusion in hypovolaemia. The list is brief for simplicity but could easily be extended for particular purposes. The doses comply with the present Resuscitation Council guidelines. If the weight is already known drug dosage may be estimated by moving directly downwards from the weight axis. If age but not weight is known dosage may be estimated by tracing across the graph and then down to the dose. If neither is known a rapid stretched out length may be measured with a tape measure and the non-linear scale above the graph used to estimate drug dosage. The chart may be made large enough to see from the resuscitation trolley or small enough to fit the pocket. Furthermore, nursing staff could use it to prepare drugs and equipment in advance of their request.

In conclusion, the variation in size of children and the comparative infrequency of cardiorespiratory arrest in this age group require some form of simple, versatile, and readily available reference chart if rapid and accurate decisions are to be made.

I thank Dr P J F Baskett, Dr A M S Black, and the consultants at the Bristol Royal Hospital for Sick Children for their helpful advice.

An A2 size poster of the paediatric resuscitation chart is available from the Publishing Department, British Medical fournal, $B M A$ House, Tavistock Square, London WC1H $9 f R$ price £3.50, including post and packing (overseas $\$ 4.50$ or US\$9). Single copies of a postcard version of the chart are also available free from the same address on receipt of an A5 size stamped addressed envelope $(16 \times 24 \mathrm{~cm}, 6 \times 9$ in $)$. For bulk orders please write to the Book Department.

1 Lowenstein SR, Libby LS, Mountain RD, Hansbrough JF, Hill DM, Scoggin $\mathrm{CH}$. Cardiopulmonary resuscitation by medical and surgical house officers. CH. Cardiopulmonary

2 Casey WF. Cardiopulmonary resuscitation: a survey of standards among junio hospital doctors. IR Soc Med 1984;77:921-4.

3 Skinner DV, Camm AJ, Miles S. Cardiopulmonary resuscitation skills of preregistration house officers. $\mathrm{Br}$ Med $\mathcal{J}$ 1985;290:1549-50.

4 Zideman DA. Resuscitation of infants and children. BrMed $\mathcal{f} 1986$;292:1584-8.

(Accepted 20 May 1988)

\title{
Psychiatric morbidity of a long stay hospital population with chronic schizophrenia and implications for future community care
}

\author{
D A Curson, M Patel, P F Liddle, T R E Barnes
}

Charter Clinic Chelsea, London SW3 4PB

D A Curson, $\mathrm{MRCPSYCH}$, medical director

\section{Shenley Hospital,} Hertfordshire

M Patel, MRCPSYCH, clinical assistant

\section{Charing Cross and Westminster Medical School, London P F Liddle, MRCPSYCH, senior lecturer \\ T R E Barnes, MRCPSYCH, senior lecturer}

Correspondence to: Dr Curson.

\begin{abstract}
In the United Kingdom there are plans to close most mental hospitals over the next $\mathbf{1 0}$ years. There is continuing uncertainty about the effectiveness of community psychiatric services that will be expected to cope with mental hospital inpatients after discharge, most of whom have schizophrenia. A survey was conducted to assess the severity of illness among such patients and implications for their future care. All 222 patients in non-psychogeriatric long stay wards of a mental hospital who met research diagnostic criteria for schizophrenia were interviewed by two psychiatrists with the comprehensive psychopathological rating scale to establish the prevalence of psychiatric symptomatology. A complete interview was not possible for 28 patients, mainly for reasons related to their schizophrenia. Despite energetic pharmacological and social treatments almost half of the 194 patients interviewed had enduring florid psychotic symptoms that presented as one or more delusions or auditory hallucinations, or both, and a sizable proportion showed behaviour that would set them apart in a community setting.

The results illustrate a problem that is still imperfectly understood by policy makers and administrators in central and local government and in health authorities who are responsible for planning and implementing services for psychiatric care in the community.
\end{abstract}

\section{Introduction}

In Europe and North America discharge of patients with chronic schizophrenia from mental hospitals began in the 1950s, before the widespread use of antipsychotic drug treatment. Avoiding admission, or early discharge, combined with domestic and industrial rehabilitation in open hospitals may prevent the accumulation of long stay "institutionalised" patients and allow a proportion of them to return to full participation in community life. ${ }^{1}$ The "therapeutic community" movement, ${ }^{2}$ best seen as an ideology rather than a therapeutic theory, did not originate in mental hospitals but spread to them later and, along with concern about institutional neurosis, ${ }^{3}$ the social breakdown syndrome, ${ }^{4}$ and asylums, ${ }^{5}$ had a considerable impact socially and politically. Thus the community care movement was born. In patients with chronic schizophrenia the success of such care depends on the validity of sociological theories about the causes of defect states; the effectiveness of new drug treatments in alleviating the acute and often bizarre symptoms of mental illness; the patients' compliance with both drug and social treatments; and the provision of suitably staffed amenities such as day hospitals, day centres, industrial units, and local hostels.

Generally the many thousands of patients with schizophrenia discharged from long stay wards in mental hospitals over the past quarter of a century have been those least impaired and most responsive to drug and social treatments. In the light of continuing uncertainty about the efficacy and effectiveness of community psychiatric services ${ }^{6}$ we describe a recent survey of an entire population of long stay patients with chronic schizophrenia in Horton Hospital, Epsom, a hospital scheduled to close within the next 10 years. 
Methods

Horton Hospital is in a semirural area south west of London; its catchment area until recently was mainly central London. For decades it received patients who have drifted into London after having been admitted to hospitals elsewhere in the United Kingdom. For over 20 years, in common with many other mental hospitals in the United Kingdom, it has pursued a vigorous policy of resettlement into the community.

During 1986 we examined the medical records of all patients in the 11 non-psychogeriatric long stay wards of the hospital to identify patients who met the criteria for a diagnosis of schizophrenia given in the Diagnostic and Statistical Manual (third edition) of the American Psychiatric Association. Two of us (DAC and MP) interviewed all patients with schizophrenia in each ward in turn by means of the comprehensive psychopathological rating scale, ${ }^{8}$ which we selected because we intended to study the nature and prevalence of depression in chronic schizophrenia. The scale covers a wide range of psychiatric symptoms, having a depression subscale (the Montgomery-Asberg depression rating scale), ${ }^{9}$ and is sensitive to change. We practised joint interviewing before and during the study to achieve high inter-rater agreement and to monitor it throughout. We used a seven point rating of severity to add to the sensitivity of the scale. Blunting and incongruity of affect were separated into two separate items. We recorded each patient's age, length of illness, and drug treatment. Patients who had developed senile dementia or were suspected of doing so were not included.

Results were analysed by the University of London's computer with the statistical package for the social sciences (SPSS).$^{10}$

\section{Results}

On completion of the survey 287 patients were resident in the 11 long stay non-psychogeriatric wards of the hospital, 239 of whom had a diagnosis of schizophrenia based on their case notes. Two hundred and twenty two fulfilled five of the American Psychiatric Association's criteria for schizophrenia,? but 10 failed to fulfil criterion $\mathrm{E}$ (onset of prodromal or active phase of illness before the age of 45), usually because of inadequate information in the case records or because their first contact with psychiatric services had been in middle age but had been preceded by years of eccentric or itinerant behaviour, or both. These 10 patients were included in the survey as they were indistinguishable in all other respects from the rest of the patients. No cases of suspected or definite senile dementia were found, but this may reflect the hospital's policy of moving such patients to higher dependency psychogeriatric wards.

A full comprehensive psychopathological rating scale could be completed on 194 patients, but 28 were not interviewed despite three attempts in each case because of persistent refusal (five), inability to speak English (four), severe thought disorder (two), mutism (13), inability to comprehend questions, including deafness (three), and absence without leave (one). In most cases the reasons for failing to interview patients were a consequence of schizophrenia, so the results we obtained from the interviews underestimated morbidity. The final item of the scale is a rating of the assumed reliability of the information obtained. In 174 cases $(90 \%)$ reliability was rated as good to very good and in the remaining cases as fair or fair to good. Inter-rater agreement based on 29 joint interviews was calculated for each item of the scale with Cohen's weighted kappa coefficient, which lay in the range $0.72-1.0$ for all items. In particular, the values of $x$ for the five items on delusions were $0 \cdot 9,0 \cdot 98,1 \cdot 0,1 \cdot 0,1 \cdot 0$ and for the two items on hallucinations 0.91 and 0.97 .

The mean age of the 194 patients interviewed was 58.7 (SD 13.7; median 60; range 24-85) years. The mean length of illness was 31 (SD 11.4; median 32; range 7-60) years.

Two main groups of items were analysed. One group consisted of all reported items reflecting "positive" psychotic symptoms. For these items scores less than 5 reflect phenomena that are not definitely delusions or hallucinations. Therefore, only patients who scored 5 or more were counted as having a particular delusion or hallucination. The other group included various observed behaviours characteristic of schizophrenia.

The seven reported items concerning psychotic symptoms were: feeling controlled (passivity experiences); having disrupted thoughts (thought insertion, withdrawal, and broadcasting and thoughts being read); ideas of persecution or grandeur (to the degree of delusion) and other delusions (ideas at least approaching the degree of delusion); auditory hallucinations, including commenting voices; and visual and other hallucinations (olfactory, somatic, and gustatory), which were rare (seven and six patients, respectively). The table shows the numbers of patients with positive symptoms of psychosis. Data for positive symptoms were missing in one case.

Data were complete for items of observed behaviours traditionally associated with chronic schizophrenia in all 194 patients. In addition to ratings of 5 or more (moderate to severe), ratings of 3 and 4 (clinically observable but mild) were also analysed because even mild behavioural disturbance might stand out in a community setting. Eighty five patients had blunting of affect, 66 involuntary movements, 28 withdrawal, 29 mannerisms and postures, 26 reduced speech, 19 incoherent speech, 14 hallucinatory behaviour, and 12 incongruity of affect.

Numbers of patients with positive psychotic symptoms at interview and severity of illness

\begin{tabular}{lc}
\hline \multicolumn{1}{c}{ Psychotic symptoms } & No \\
\hline & \\
Delusion(s) only & 43 \\
Auditory hallucinations only & 16 \\
Coexisting delusion(s) and auditory hallucinations & 47 \\
\hline Total delusions with or without auditory hallucinations & 90 \\
Total auditory hallucinations with or without delusion(s) & 63 \\
\hline \multicolumn{1}{c}{ Global rating of severity of illness } \\
Moderate and definite & \\
Severe or incapacitating & 65 \\
Intermediate (between moderate and severe) & 21 \\
\hline Total & 33 \\
\hline
\end{tabular}

\section{Discussion}

In the United Kingdom most if not all mental hospitals, including Horton Hospital, are planned to close over the next 10 years and their present long stay patients (mainly those with chronic schizophrenia) will be discharged to community care. The two most recent systematic and detailed assessments of morbidity among long stay populations in mental hospitals in the United Kingdom have been of patients in Shenley Hospital, ${ }^{11}$ and of 571 new long stay patients in 14 mental hospitals in Scotland. ${ }^{12}$ Neither of these studies attempted to assess psychotic symptoms with the degree of detail possible with the comprehensive psychopathological rating scale; none the less, both showed that most long stay inpatients had substantial psychiatric symptomatology and associated disability. A survey at another mental hospital in London (Friern Hospital), in which the present state examination ${ }^{13}$ was used, gave similar results to ours (J P Leff et al, personal communication). 
The comprehensive psychopathological rating scale is less specific than the present state examination in eliciting detailed psychopathology, yet it is still based on a detailed interview lasting 30-45 minutes. One of us (DAC) had taught the interview technique of the present state examination for eight years and trained the other interviewer (MP), with the result that our ratings were based on this interview technique, with the same probe questions and a high threshold for abnormality. This may account for the high inter-rater agreement and the high assumed reliability of the interviews.

A substantial proportion of the study population consisted of elderly schizophrenic patients who had been in hospital for many years, were resistant to conventional (and often energetic) drug treatment, and had proved difficult to resettle in the community. Such patients accumulate particularly in hospitals like Horton and Friern because of the well known drift of vulnerable people to anomic city areas; nevertheless, such patients are seen everywhere, though at a lower rate.

Our survey showed that despite the best attempts at alleviating or controlling positive symptoms of schizophrenia almost half of the patients had one delusion or auditory hallucinations, or both, and we rated nearly two thirds as being moderately to severely mentally ill. A sizable proportion showed abnormalities of behaviour that may pass almost unnoticed in a mental hospital but would set a person apart in the community. When the patients who could not be interviewed were included the morbidity increased: 13 of these patients were mute, two had severe thought disorder, and for the five who persistently refused to be interviewed the reason was undoubtedly related to their schizophrenia. In addition, patients who were interviewed may not have shown all of their active psychotic symptoms.

Positive and negative psychotic symptoms are related to social behaviour, ${ }^{14} 15$ although social performance is not a measure of schizophrenic deficit. Schizophrenic deficit is, however, an important cause of poor social functioning; nevertheless, symptoms such as blunting of affect and poverty of speech cannot be regarded as immutable. ${ }^{16}$ Detailed assessment of social functioning in our population is currently under way.

As hospitals such as Horton close the community psychiatric services will have to cope with an influx of many aging and socially handicapped patients with chronic schizophrenia, many of whom have been in hospital for decades and are partially or completely resistant to treatment. In the early 1960s the original optimism and enthusiasm for community care of long term mentally ill patients were based on an assumption that antipsychotic drug treatment would be more effective than has proved to be the case. For example, in the United States the first attempt to evaluate scientifically the role of antipsychotic drugs in the community showed that patients with chronic schizophrenia could survive better out of mental hospital when maintained on oral antipsychotic drugs than on placebo. ${ }^{17}$ Even then, however, for the future success of a community programme for mental health the study cautioned against relying heavily on the efficacy of new drug treatments and on the ability and willingness of families to tolerate deviant or asocial family members, and pointed out the need for highly trained and deeply committed community staff to help patients through periodic episodes of acute symptoms.

A classic study in three mental hospitals in the United Kingdom found that "negative" symptoms of schizophrenia, such as poverty of emotional response and speech, and low volition, correlated with social withdrawal and were associated with an environment that was not sufficiently stimulating. ${ }^{\prime}$ Increased environmental stimulation during follow up was associated with some reduction in negative symptoms, but these were a severe handicap in patients discharged into the community. When the demands of that environment exceeded the patients' ability to cope many had to be readmitted because of depression, anxiety, or florid symptoms. ${ }^{18}$

The extent of problems with compliance once patients were discharged had also been underestimated. Poor compliance with oral treatment in an estimated $40-45 \%$ of patients began to be reported in the 1960 s. $^{1920}$ Drug trials tended to recruit self selected regular attenders at special maintenance clinics, resulting in artificially low estimates of poor compliance. ${ }^{21-24}$ About a third of patients newly treated with long acting injectable drugs after discharge did not comply. Later, in a seven year follow up study of a trial of depot injections in which poor compliers had been excluded before entry ${ }^{25}$ long term compliance problems were found in $40 \%$ of the patients. ${ }^{26}$

In the United Kingdom claims of underfunding as the main obstacle to adequate community services should be tempered by criticism of poor coordination of services in the late $1960 \mathrm{~s}$, which may have contributed to a high rate of readmission, even when financial support for mental health was readily available from local government. ${ }^{27}$ The report by Griffiths, 20 years later, identified the same shortcomings. ${ }^{28}$

Undoubtedly a substantial proportion of patients in mental hospitals will have difficulty coping outside the hospital, and many already have problems coping within such a protected environment. Not only will community psychiatric services have to be well organised but inpatient facilities, albeit at a local level, will be required to offer genuine asylum for the patients who are most severely ill and have irreversible conditions: one such model is the Haven Community concept ${ }^{29}$ in which the needs of patients are based on their social disablement.

The prevalence of active psychotic illness and behavioural disturbance evident in this study despite energetic drug and social treatments forewarns of the problems that lie ahead if community services are insufficiently comprehensive and insufficiently organised and funded.

We thank the staff and patients of Horton Hospital, Epsom, for their help and cooperation, the referees for their advice, and Sally Musk for the typing.

1 Wing JK, Brown GW. Institutionalism and schizophrenia. Cambridge: Cambridge University Press, 1970.

2 Jones M. Social psychiatry: a study of therapeutic communities. London: Tavistock, 1952.

3 Barton R. Institutional neurosis. Bristol: Wright, 1959.

4 Gruenberg EM (ed). Evaluating the effectiveness of community mental health services. New York: Millbank Memorial Fund, 1966.

5 Goffman E. Asylums: essays on the social situation of mental patients and other inmates. New York: Doubleday, 1961.

6 Murphy E. Community care I: problems. Br Med f 1987;295:1505-8.

7 American Psychiatric Association. Diagnostic and statistical manual of mental disorders. 3rd ed. Washington, DC: American Psychiatric Association, 1980

8 Asberg M, Montgomery SA, Perris C, Schelling D, Sedvall G. A comprehensive psychopathological rating scale. Acta Psychiatr Scand 1978;57(supp 271):5-27

9 Montgomery SA, Asberg M. A new depression scale designed to be sensitive to change. Br F Psychiatry 1979;134:382-9.

10 Nie NH, Hull CH, Jenkins JG, Steinbrenner K, Bent D. The statistical package for the social sciences (SPSS). 2nd ed. New York: McGraw Hill, 1975.

11 Owens DC, Johnstone EC. The disabilities of chronic schizophrenia: their nature and the factors contributing to their development. Brf Psychiatry 1980;136:384-95.

12 McCreadie RG, Wilson OA, Burton IL. The Scottish survey of "new chronic" inpatients. Br f Psychiatry 1983;143:564-71.

13 Wing JK, Cooper JE, Sartorius N. The measurement and classification of psychiatric symptoms. Cambridge: Cambridge University Press, 1974.

14 Stevens BC, The role of fluphenazine decanoate on lessening the burden of chronic schizophrenics in the community. Psychol Med 1973;3:141-58.

15 Curson DA, Barnes TRE, Bamber RW, Platt SD, Hirsch SR, Duffy JC. Long term depot maintenance of chronic schizophrenic outpatients. The seven year follow up of the Medical Research Council fluphenazine/placebo trial. III. Relapse postponement or relapse prevention? The implications for long term outcome. Brf Psychiatry 1985;146:474-80.

16 Wing JK. Relapse in schizophrenia. Br Med f 1985;291:1219-20. 
17 Pasamanick B, Scarpitti FR, Lefton $M$, Wernert JJ, McPheeters H. Home vs hospital care for schizophrenics. $\mathcal{F} A M A 1964 ; 187: 177-81$.

18 Gaind R, Barnes TRE. Depot clinics. In: Praag HM van, Lader MH, Rafaelson OJ, Sacher EJ, eds. Handbook of biological psychiatry, part VI. Practical applications of psychotropic drugs and other biological treatments. New York: Dekker, 1981:149-79.

19 Anonymous. Long acting phenothiazines in schizophrenia [Editorial]. $\mathrm{Br} \mathrm{Med}$ f 1971;i:189-90.

20 Renton CA, Affleck JW, Carstairs M, Forrest AD. A follow up of schizophrenic patients in Edinburgh. Acta Psychiatr Scand 1963;39:548-600.

21 Leff JP, Wing TK. Trial of maintenance therapy in schizophrenia. $\mathrm{Br} \mathrm{Med} \mathcal{F}$ 1971;iii:599-604.

22 Johnson DAW. The expectation of outcome for maintenance therapy in chronic schizophrenics. Br f Psychiatry 1976;128:246-50.

23 Falloon I, Watt DC, Shepherd M. A comparative controlled trial of pimozide and fluphenazine decanoate in the continuation therapy of schizophrenia. and fluphenazine decanoate in

24 Barnes TRE, Milavich G, Curson DA, Platt SD. The use of the social behaviour assessment schedule (SBAS) in a trial of maintenance anti- psychotic therapy in schizophrenic outpatients: pimozide versus fluphenazine. Soc Psychiatry 1983;18:193-9.

25 Hirsch SR, Gaind R, Rohde OD, Stevens BC, Wing JK. Outpatien maintenance of chronic schizophrenic patients with long-acting fluphenazine: double blind placebo trial. Br Med F 1973;i:633-7.

26 Curson DA, Barnes TRE, Bamber RW, Platt SD, Hirsch SR, Duffy JC. Long term depot maintenance of chronic schizophrenic outpatients. The seven year follow up of the Medical Research Council fluphenazine/placebo trial. II. The incidence of compliance problems, side effects, neurotic symptoms, and depression. Br f Psychiatry 1985;146:469-74.

27 Crumpton $\mathrm{N}$. The role of drugs in maintaining patients in the community. In: David GR, Freeman HL, eds. Treatment of mental disorders in the community. London: Baillière, Tindall and Cassell, 1968:15-24.

28 Griffiths R. Community care: agenda for action. London: HMSO, 1988.

29 Wing JK, Furlong R. A haven for the severely disabled within the context of a comprehensive psychiatric community service. Br f Psychiatry 1986;149: $449-57$.

(Accepted 9 fune 1988)

\title{
Transabdominal chorionic villus biopsy in second and third trimesters of pregnancy to determine fetal karyotype
}

\author{
L Pijpers, M G J Jahoda, A Reuss, J W Wladimiroff, E S Sachs
}

\begin{abstract}
Transabdominal chorionic villus biopsy is an established method of obtaining material for analysing fetal chromosomes in the first trimester of pregnancy but has not been widely used for karyotyping in the second and third trimesters, when rapid results are required. The technique was evaluated in two groups of patients, comprising 106 at risk of having a fetus with chromosomal anomalies (105) or $\mathrm{X}$ linked disease (one) studied between 13 and 22 weeks (median 15 weeks) of gestation (group 1) and 21 with abnormal fetal findings on ultrasonography studied between 13 and 38 weeks (median 27 weeks) (group 2). Chorionic tissue was collected at the first attempt in 109 patients and at the second attempt in a further 17 independent of the position of the placenta. In one case from group 1 sufficient material for analysis could not be obtained. Seven abnormal karyotypes (six in group 1 and one in group 2) were diagnosed. Karyotyping was unsuccessful in two cases in group 1 (at 17 and 18 weeks' gestation) and in two in group 2 (at 29 and 38 weeks' gestation). Follow up of group 1 four weeks after sampling showed no signs of adverse fetal development apart from one unexplained intrauterine fetal death.
\end{abstract}

The findings suggest that chorionic sampling is a safe and valuable additional technique for the late detection of chromosomal defects.

\section{Introduction}

Transabdominal and transcervical sampling of chorionic villuses during the first trimester of preg-

Department of Obste University Hospital

Rotterdam-Dijkzigt, 3015

GD Rotterdam, The

Netherlands

L Pijpers, MD,

gynaecologist

M G J Jahoda, MD,

gynaecologist

JW Wladimiroff, MD,

professor

Department of Clinical

Genetics, Erasmus

University, Rotterdam,

The Netherlands

A Reuss, MD, research fellow

E S Sachs, MD, clinical

geneticist

Correspondence to:

Professor Wladimiroff.
Renal anomalies

Non-structural defect:

Fetal hydrops

Severe growth retardation
Hygroma colli nancy are highly effective and reliable techniques in detecting fetal diseases. ${ }^{12}$ Whereas sampling during the first trimester allows karyotyping to be performed within 36 hours after the procedure, karyotyping in the second and third trimesters is still mainly carried out on amniotic cells obtained by amniocentesis, with the disadvantage that the results are not available until two or three weeks later. This delay is particularly unacceptable in late pregnancy, when knowing the fetal karyotype is essential for obstetric management if certain structural defects are present in the fetus.

Preliminary reports suggest that transabdominal chorionic villus sampling may be useful for rapid fetal karyotyping in late pregnancy. ${ }^{3.5} \mathrm{We}$ present our experience with this technique for rapid karyotyping in the second and third trimesters.

\section{Patients and methods}

Between February and October 1987 we carried out transabdominal chorionic villus sampling in two groups of patients (table I). One group consisted of 105 patients who had a fetus at risk of chromosomal anomalies and one whose fetus was at risk of the $\mathrm{X}$ linked abnormality Paine's syndrome (group 1); the median gestational age was 15 weeks (range 13-22 weeks). The other group comprised 21 patients with abnormal fetal findings on ultrasonography (group 2); the median gestational age was 27 weeks (range 13-38 weeks). We explained the technique and its purpose to the patients and their partners.

The procedure started with identification of the placenta. After disinfection of the skin a 20 gauge spinal needle without a stylet (TSK Supra, West Germany) flushed with heparin was attached to a $20 \mathrm{ml}$ syringe filled with $5 \mathrm{ml}$ RPMI medium and introduced into the placenta under continuous ultrasound guidance with a linear array real time scanner (Hitachi, transducer carrier frequency $3.5 \mathrm{MHz}$ ). The transducer was close to the site of insertion and so had been disinfected with povidone-iodine spray. Sterile gloves and contact gel were used throughout the procedure. Within the placenta the tip of the needle was placed close to the chorionic membrane and slowly moved vertically and obliquely under a continuous vacuum. The chorionic tissue collected was dissected immediately by an experienced technician; at least $10 \mathrm{mg}$ of tissue was needed for karyotyping. During the procedure the needle was not inserted more than twice. When the maternal blood group was $\mathrm{Rh}$ negative we gave a single intramuscular dose of rhesus immunoglobulin $125 \mu \mathrm{g}$ directly after the procedure. 